
by a punctured wound of the hand. Digitalis was largely
given in this case.

On the 24th of November, 1853, Mr. Joseph Bainbridge Fife saw John Peray, aged thirty-one, with extensive laceration of the palmar fascia, and complete separation of the metacarpal bone supporting the thumb from that of the forefinger. It was determined to try to save the hand; and all went on well until the 2nd of December, when trismus appeared, and gradually increased in the violence and frequency of the spasms. On the 16 th, retention of urine was complete; and the catheter was constantly used until the 21 st, when the spasms (tetanic) became less frequent and less severe. In this case, turpentine dressings, covered with poultices, were applied to the hand. The man is at this time in perfect health.

The fourth case, which occurred in my own practice, was as follows:-G. G - aged twenty-seven, a strong man, of sanguine temperament, on the 23rd of August, 1854, while riding, was thrown from his horse, and received a contused wound on the knee, just over the superior edge of the patella. The wound appeared little more than a deep graze; but after the lapse of a few days, during which poultices were applied, great swelling having taken place on each side of the knee, a slough separated, disclosing a deep but healthy-looking ulcer. On examination, the integument was found to be separated from the parts beneath to the extent of three inches, on either side of the knee; and, by pressure, a great accumulation of healthy-looking pus was discharged. Nothing worthy of notice occurred up to the evening of the 9th of September, when my attention was directed to a slight stiffness in the action of the jaw; the ulcer, too, which had up to this time been covered with healthy pus, presented a dry appearance, the edges being of a dark red, approaching to livid. He complained of a slight cold, which he attributed to his having approached the open window without his coat. The bowels being costive, I ordered him calomel, two grains; compound extract of colocynth, eight grains; immediately: to be followed three hours after by a black draught. The jaw to be fomented, and rubbed with a liniment, composed of liquor of opium, two drachms; and compound soap liniment, ten drachms. The bowels were freely opened from the purge; but the stiffness of the jaw continued to increase almost imperceptibly till the night of the 14th, when symptoms of acute tetanus set in, spasms occurring at intervals of very few minutes. Early in the morning of the 15th, I was sent for, and procured the assistance of Sir John Fife. We dressed the wound with chloroform, covered by a poultice; and prescribed a febrifuge mixture, with twenty minims of tincture of digitalis at a dose, every three hours : a blister between the seat of injury and the spinal cord: and pills, containing calomel, four grains; and opium, one grain and a half: to be taken every three hours. The jaw being now constantly almost closed, we ordered friction every three hours, with a liniment of equal parts of compound soap liniment and tincture of aconite. The pulse, which had hitherto never exceeded 90 , during the night of the 14 th reached 120 .

Sept. 16th. - He had passed a very restless night, sieep being entirely prevented by the frequency of the spasms; pulse 100 ; bowels slightly relieved, stool liquid, very dark-coloured, and offensive; spasms not so frequent as during the night; complains of tension of the abdomen, causing vomiting. The muscles of the face towards evening were much relaxed; mouth open to the extent of three-quarters of an inch; can drink easily.--Ten P.M.: Symptoms all somewhat increased. Twelve P.M. : slightly delirious; spasms violent every four or five minutes.

17th, Four A.Mr.-Pulse 108; sleeps half an hour at a time between the spasms; complains, in passing urine, of the stream stopping suddenly, apparently from spasm. - Six A. M. : Pain in the bowels, and is sick eight or nine times within half an hour, the breath has slight mercurial foetor. Reduced the dose of calomel to one grain and a half. - Eight P. M. : Pulse 96 ; spasms of abdominal muscles seem somewhat increased; purged, stools slightly tinged with blood.

18th. - Pain in the bowels, purging, and bloody stools, still continue; pulse 104, very weak; mercurial action fully established; severe spasms only precede evacuations from the bowels; the wound suppurating freely. Applied another blister in the same line with the former one, to be dressed with savine ointment: ordered the calomel to be discontinued, and one grain of muriate of morphia at night: and a mixture composed of liquor of acetate of ammonia, two ounces; tincture of digitalis, two drachms; water, six ounces; one ounce evory three hours; and a pill every three hours also, composed of one grain of opium, and three grains of carbonate of ammonia. He has drunk half a bottle of sherry in the course of the day, and also a good deal of beef-tea. 20th. - Spasms during the day rather frequent, but not so severe, and principally affecting the lower extremities; pulse from 100 to 140 .

25th. - Since last date the spasms have been gradually decreasing in force and frequency, and he is now able to stop the spasm of the leg, by grasping tightly the superior part of the thigh.

From this time no bad symptom made its appearance; the wound healed easily, and he is at this moment in the enjoyment of his usual health.

All these cases exhibit one feature in common-viz, the amelioration of the disease on the appearance of mercurial action, and the chronic form of tetanus which followed led to convalescence by slow degrees. Although in one case bleeding was used, in another digitalis, in a third turpentine dressing, and in a fourth chloroform (topically), yet the four cases were all treated with calomel and opium, and the first sign of the dimition of the disease was cotemporary with the tenderness and swelling of the gums.

Houghton-le-Spring, Durham, 1855.

ON A

\section{CASE OF MALIGNANT CHOLERA.}

BY JOHN C. BARRY, Esq.

RESIDENT MEDICAL OFFICER OF THE BASTERN DISPEASARY.

THomas $\mathrm{J}$ - aged thirty-seven, residing in Rosemary lane, Tower-hill, a dirty and crowded locality, a dock-labourer, of full habit of body and sanguine temperament, somewhat in temperate in his habits, applied to me on the 11th of July, when, according to his account, he had been for one week previously suffering from constant diarrhœa. He did not complain of any pain ; neither was there any tenderness on pressure over the abdominal region. The only inconvenience, as he expressed it, being the constant purging, which rendered him weak and not so fit for his work as usual. Pulse 86 , soft, and somewhat compressible; tongue white on the dorsum, and red at the tip and edges; skin warm and moist. He is somewhat thirsty, and has little or no desire for food, but drinks, as customary, a good deal of beer. I prescribed for him the following draught tincture of catechu, one drachm; compound tincture of rhubarb, half a drachm; tincture of opium, ten minims; clovewater, one ounce: to be taken three times a day. To abstain from beer, and confine himself to milk-and-water, arrow-root, and rice, with a small quantity of brandy-and-water.

June 12 th. - His wife called this morning to say that he had passed a very bad night, and had been obliged to leave his dock employment. Yesterday she expressed a wish that I should see him. I visited him at two P.K., and found that he had been constantly sick during the night, drinking large quantities of cold water, but as frequently vomiting it up again. He was in great pain in the abdominal region, which was slightly relieved on pressure; cramps in the hands and feet coldness of the extremities; the surface of the body covered with a cold, clammy sweat; anxions expression of countenance. The evacuations from the bowels presenting the ricewater appearance; the urine suppressed; did not rest, but kept throwing himself about in the bed. Pulse 160, small, weak, thready, and compressible; tongue white, somewhat cold and flabby. He has had no sleep all night, and appears quite indifferent to everything around him. I prescribed the following: chloride of mercury, ten grains; opium, two grains: to be administered directly, on sugar. To be followed, in half an hour, by two grains of calomel, with a quarter of a grain of opium, every two hours. A large mustard cataplasm to the abdominal region; bottles of hot water to the feet and in the axillæ: to have a little brandy-and-water; also milk-andwater at intervals. - Four P.M. : He has slept for about an hour since taking the powder, and is free from pain in the abdomen, although the cramps in the feet continue. The surface of the body is much warmer than it was; the tongue somewhat brown on the dorsum, and red at the tip and edges; pulse 140, small, weak, and compressible; urine still suppressed; he is constantly purged, the stools presenting the ricewater appearance still. He continues to be sick, but not so frequently; and is more composed; cannot take the brandyand-water; is ordered beef-ten instead. To continue warmth to the extremities and in the axilla, and to apply the mustard cataplasm to the abdomen should the pain return. -Eight P.M.: He is better, though not quite free from cramps; keeps the beef-tea down, and has not had any 
sickness; is still purged; has not passed any urine. The surface of the body is warmer, although somewhat cold and clammy; the pulse is still small, frequent, and compressible; tongue brown on the dorsum, red at the tip and edges, and he feels more comfortable.

July 13th. - Eleven A.M.: He has passed a comfortable night, and is quite free from cramp and pain; has still a good deal of thirst, but no sickness; passed his urine at two o'clock this morning; he is still purged, but the motions are now tinged with bile; tongue clean, though somewhat brown on the dorsum; pulse 98 , full, frequent, and compressible. He expresses himself as getting better, though still very weak. The surface warm and perspiring.-Six R.M.: Is doing very well. The gums slightly sore from the mercury.

14th. - Twelve A.M.: He is now convalescent, although slightly feverish. Pulse 78, regular; tongue clean; bowels very little relaxed, and presenting a healthy appearance. Discontinue the calomel and opium.

20th. - He has been going on well since the 14th, and thinks of resuming his occupation in a few days; he is now taking compound tincture of cardamoms, one drachm; aromatic spirits of ammonia, half a drachm; water, one ounce: three or four times a day.

\section{INTUSSUSCEPTION._-SLOUGHING OF A PORTION OF ILEUM.}

By JOHN SANG, Esq., M.R.C.S.

I wAS requested to visit Jane A-, aged twelve, on the evening of the 29th of April, 1855. She complained of great pain in the right side, a little below the ribs. There was evident enlargement, about the size of a goose's egg, which gave severe pain upon pressure, and was attributed to carrying a heavy basket of potatoes, which pressed much upon the side. She suffered also severely from vomiting.

Leeches were ordered, to be followed by a large poultice with small doses of calomel and opium, which gave partial relief. Other medicines of a laxative nature were given to her, but these she repeatedly vomited, and, indeed, almost everything was rejected, and in consequence [ left off giving medicine, as it only seemed to aggravate the disease.

On the 3rd or 4th of May, vomiting of feculent matter commenced, and continued almost daily until the 17th. The bowels were much distended, painful, and tympanitic. A large blister was applied, and occasionally turpentine, outwardly, and by injection. Injections of soap-and-water were used two or three times a day, with warm applications over the bowels, and on the morning of the 9 th of May a portion of the ileum, about twelve inches in length, was passed per anum. For two or three days after this she was comparatively easy; had no vomiting; bowels acted naturally, but there was considerable difficulty in passing urine; pulse 112 ; tongue moist

May 14th. - Slight vomiting of feculent matter; bowels freely moved by injection. Slept tolerably well.

15th.-No vomiting; restless in the night; bowels slightly moved by injection; passed urine more freely, and was much relieved; pulse 114; bowels still large and painful. Poultices were almost daily applied.

16th. - No vomiting; otherwise much as yesterday.

17th. - Vomited a large quantity of feculent matter last evening; afterwards passed a good night; urine more copious; very weak. The food to be entirely of a farinaceous character.

18th.--Vomited again last evening; passed a quiet night; tongue moist; pulse 120 .

19th. - No vomiting; bowels twice naturally moved; pulse 104. 21st. - Continues to improve.

24th. - No vomiting since the 17th; used an injection occasionally; pulse gradually coming down.

June 1st. - Doing well; no bad symptoms.

14th. - Quite recovered; bowels act naturally. Her health is better now than it has been for some years; her appetite is very good, but still restricted chiefly to farinaceous diet, and ccasionally a little beef-tea.

It appears that at the age of two years she had symptoms of marasmus, and continued in a very weak state of health for three or four years. Since that time she has frequently complained of pain in her bowels, followed occasionally by severe purging usually in the spring of the year.

Such is a brief outline of the case. No doubt, in the first instance, it had been one of intussusceptio, but Nature had exerted her wonderful restorative powers, and satisfactorily completed what the ingenuity of man would fail to do.

Newcastle-upon-Tyne, 1855 . dy a

OF THE PRACTICE OF

\section{MEDICINE AND SURGERY IN THE}

\section{HOSPITALS OF LONDON.}

Nulla est alia pro certo noscendi via, nisi quam plurimas et morborum e comparare-Morgagri. De Sed. et Caus. Morb. lib. 14. Prommium.

\section{ST. BARTHOLOMEW'S HOSPITAL.}

THE SEAT OF STRICTURE IN FEMORAL HERXIA; OPERATIOY ON THE NECK OF THE SAC.

(Under the care of Mr. STANLEY.)

Amongs the later and more valuable facts in connexion with hernia are, perhaps, the hospital statistics of the number of cases where the old sac of an old hernia has undergone obliteration, from the effect of various forms of apparatusneedles, setons, \&c., run through the sac, inverted like the finger of a glove, or, as now generally termed, like the analogous proceeding in hydrocele,-the "radical" cure of hernia, and chiefly applicable in cases of inguinal hernia. Wutzer, of Munich, has, within a few years, tried the plan in 400 cases, without any evil result, 390 having had their hernia entirely and radically removed. The sac of the hernia was thus obliterated, and all danger of the hernia becoming strangulated subsequently, as well as the tendency of the hernia to descend again and again, was thus entirely prevented.

We were reminded of the value of the method of invagina. tion, so familiar now to most surgeons, by a case of femoral hernia operated on, a few days since, by Mr. Stanley. A. Saged forty-five, admitted August 5th, with sickness of stomach and confinement of the bowels, of a week's duration. The patient did not present many of the other symptoms of hernia; the latter, however, was plainly to be felt at the groin. She had no anxiety of countenance, so common in hernia; her tongue was clean; pulse quiet. She was ordered a warm bath, and the taxis was carefully tried, but as none of these means succeeded in returning the bowel, Mr. Stanley decided to operate before more serious symptoms set in. Having been placed under the influence of chloroform, Mr. Stanley found, on cutting down, a state of parts quite extraordinary and unusual, and as such, we believe, deserving of notice. In this case, the neck of the sac of the hernia seemed to have strangulated the gut in its descent, the latter having taken place, also, not through the usual femoral ring, but external to it, and in front of the femoral vein, leaving Gimbernat's ligament, the upper extremity of the falciform ligament, and the femoral ring, all quite free, and to the inside. The stric. ture, Mr. Stanley believed, had taken place in the neck of the sac itself, the hernia thus coming down, we need scarcely add, in close and dangerous proximity to the femoral artery on the outside. Mr. Stanley had previously found the femoral hernia, in some other rare instances, in the sheath of the vessels, so he was not entirely unprepared for the state of things in the present case. The mode of operation required great care. It was not the obturator artery, of course running round the neck of the sac, but the femoral itself, in close proximity, that con, stituted the danger. It was not a division of Gimbernat's ligament in the pectineal line, or the falciform ligament, which now seemed necessary to be cut; both were felt and seen by Mr. Stanley to be not at all engaged in producing the stricture, the latter being seated more correctly, perhaps, in the neck of the sac, as we have just said, and in the contiguous parts of the fascia transversalis. Acting on these views, Mr. Stanley fortunately had little difficulty in returning the bowel, and the woman has since done very well. It is scarcely necessary to give the case in extenso, as this formed the chief peculiarity and difficulty in the case; and after a few doses of opium, fol. lowed by mild aperients, the recovery has been quite satis. factory. 